\title{
ESTUDO SOBRE CREDENCIAMENTO DE INTERNATOS PARA PESSOAS IDOSAS *
}

\author{
Ernestine Maurer Bastian *:
}

BASTIAN, E. M. Estudo sobre credenciamento de internatos para pessoas idosas.

Rev. Saúde públ., S. Paulo, 14:439-53, 1980.

RESUMO: Estuda-se internatos para pessoas idosas com o objetivo de verificar se internatos com maior capacidade fisica, em termos de número de leitos, oferecem assistência mais completa aos seus residentes, do que estabelecimentos pequenos. Foram estudados os seguintes aspectos: planta fisica, instalações e equipamentos, programação de atividades e pessoal técnico a disposição. Os resultados da pesquisa respondem a pergunta formulada positivamente para a maioria dos itens examinados.

UNITERMOS: Internatos para idosos.

\section{INTRODUCAO}

A problematica geriátrica ell paises de populaçós chamadas "jovens" é apresentada em publicaçoes da OMS (1974 1i; $1974^{14}$ ) com dados que devem orientar a assistência a ser prestada à população idosa desses países.

Segundo a OMS, a tendència de acentua. do envelhecimento da população mundial nas próximas décadas será mais significativo nos paises em desenvolvimento do que nos paises desenvolvidos.

Assim, enquanto se estima o crescimento da população mundial de pessoas com 60 e mais anos de idade, do ano 1970 ao ano 2000 , de $8 \%$ a $9 \%$, ou seja, na razão de $1 \%$, o dos países em desenvolvimento será de $5,4 \%$ a $7 \%$, correspondendo a uma razão de $1,6 \%$.

Outro fato apontado pela OMS (1974 1i), é que o aumento tanto do número absoluto como a proporção das pessoas de idade de 80 anos em diante será o mais acentuado.

Obvio é que paralelamente com este crescimento far-se-ão necessários os recursos especiais para esta população. Isto porque, mesmo supondo que família e autoridade farão o possivel para que o idoso possa viver o máximo de tempo possivel com independência na comunidade, com o avançar da idade acentuam-se os problemas de saúde e os a eles relacionados, neces-

* Res:mo da Tese de Livre-docéncia apresentada à Faculdade de Saúde Pública da USP. em 1979. subordinada ao título "Estudo sobre acreditação de internatos para pessoas idosas na área metropolitana de Porto Alegre. RS".

* Do Departamento de Prática de Saúde Pública da Faculdade de Saúde Pública da USP Av. Dr. Arnaldo, 715 - 01255 - São Paulo, SP - Brasil. 
BASTIAN, E. M. Estudo sobre credenciamento de internatos para pessoas idosas. Rev. Saúdo públ., S. Paulo, 14:439-53, 1980.

sitando a provisão de recursos institucionais (Herz, 1971 ${ }^{6}$; Karcher e Linden, $1974^{10}$; Leeds e Shore, $1964^{11}$; Muenchen, $1972^{12}$; OMS, $1974^{17}$ ).

Tais instituições, muitas vezes, nascem espontaneamente das necessidades imediatas da comunidade, sem que haja padrões estabelecidos ou controlados para as condições de vida a serem oferecidas aos residentes.

Existe nos EUA o "Conselho Nacional para Acreditação de Internatos para Idosos" (Holle, $1968^{7}$ ), e há programas universitários para treinamento de "inspetores" dessas instituições.

No Brasil está sendo desenvolvido o "Programa Assistencial ao Idoso em Inter-

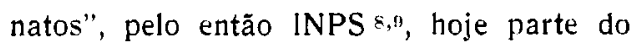
SINPAS, Sistema Nacional de Previdência e Assistência Social, atualmente executado pela Fundação Legião Brasileira de Assistência. Este programa utiliza-se de um instrumento de "Classificação de Instituições para Idosos" com o fim de avaliar a elegibilidade de internatos para convênios.

No presente trabalho utiliza-se este instrumento e após um teste aplicado a uma amostra dos internatos visados, elabora-se um modelo em alguns aspectos modificado e ampliado, para ser utilizado na pesquisa. Denominou-se o novo instrumento de "Modelo de Credenciamento", em substituição ao termo "Acreditaçāo", usado por Ciari Jr. $1974^{3}$. (Em anexo).

O presente estudo teve como objetivo a verificação da hipótese de que estabelecimentos com maior capacidade física oferecem assistência mais completa aos seus residentes, do que internatos pequenos. Esta hipótese foi também levantada por vários autores (Bastian, $1977^{1}$; Beatty $\mathrm{e}$ Bullok, $1964^{2}$; Greenwald e Linn, $1934^{4}$; Sirocco, 1972 ${ }^{16}$; Weihl e Ashkenazi ${ }^{18}$, 1975).

\section{MATERIAL E METODOS}

O trabalho se ocupa com internatos da área metropolitana de Porto Alegre, RS. Do universo de 29 estabelecimentos, relacionados no Catálogo de Obras Sociais ${ }^{15}$, 4 não puderam ser localizados, restando 25 internatos. Para o teste do instrumento original foram amostrados $20 \%$, respostos depois ao universo para o estudo definitivo.

Efetuou-se então uma análise em profundidade dos recursos de relevância para a atenção eficaz e eficiente aos residentes, representados:

- pelas condições da planta física do estabelecimento;

- por suas instalações e equipamentos;

- pela importante área da programação de atividades dos residentes;

- pelo não menos importante pessoal técnico à disposição para assistência global à clientela.

Dois entrevistadores treinados para as entrevistas com os responsáveis pela direção dos internatos visitaram os estabelecimentos durante 3 semanas, em 5 dias cada uma. A duração média das visitas era de $40 \mathrm{~min}$, com uma amplitude de $20 \mathrm{~min}$ a $2 \mathrm{~h}$, dependendo da menor ou maior complexidade do estabelecimento.

No tratamento estatistico dos dados obtidos, foi utilizado o coeficiente de correlação ordinal de Spearman, para verificar se há uma relação significante entre os valores obtidos no credenciamento e o número de leitos nas instituições.

Para a classificação dos internatos segundo os pontos obtidos, na aplicação do "Modelo de Credenciamento" considerou-se:

\begin{tabular}{|c|c|c|}
\hline & Pontos & Classificação \\
\hline 100 & -80 & ótima \\
\hline 80 & -60 & boa \\
\hline 60 & -40 & regular \\
\hline 40 & a menos & má \\
\hline
\end{tabular}


BASTIAN, E. M. Estudo sobre credenciamento de internatos para pessoas idosas. Rev. Saúde públ., S. Paulo, 14:439-53, 1980.

\section{RESULTADOS}

Apresentam-se os valores de credenciamento em termos de pontos máximos possíveis e de pontos obtidos, e as classificações obtidas pelos internatos, primeiro em relação aos componentes das áreas investigadas, e ainda em vista do número de leitos, ou seja, de sua capacidade física.

\section{Planta física}

O conjunto dos componentes da planta física, Tabela 1 , obteve $65,54 \%$ dos pontos máximos possíveis, o que corresponde a uma classificação "boa".

O componente de melhor classificação, ou seja, o único com "ótimo", com 85,32 pontos, é a "unidade de administração"; o

TABELA 1

Pontos máximos possiveis e pontos obtiłos pelos grupos de internatos agrupados, referente ao item I Planta Física, segundo componentes, na área metropolitana de Porto Alegre, RS, 1978.

\begin{tabular}{|c|c|c|c|c|}
\hline \multirow{2}{*}{ Componentes da planta física } & \multicolumn{2}{|c|}{ Pontos * } & \multirow{2}{*}{$\begin{array}{c}\% \\
\text { Obtenção }\end{array}$} & \multirow{2}{*}{ Classificação } \\
\hline & $\begin{array}{c}\text { Máx. } \\
\text { possivels }\end{array}$ & Obtidos & & \\
\hline A - Edificação & 500 & 400 & 80,00 & Boa \\
\hline B - Acesso ao prédio & 750 & 370 & 49,33 & Regular \\
\hline $\mathrm{C}$ - Acesso às dependências & 750 & 290 & 38,66 & Má \\
\hline D - Areas externas & 1000 & 640 & 64,00 & Boa \\
\hline E - Recreação & 1000 & 480 & 48,00 & Regular \\
\hline$F$ - Unidade de Adminisração & 2250 & 1920 & 85,32 & otima \\
\hline G - Dependências privativas dos & 2500 & 1635 & 65,40 & Boa \\
\hline Total & 8750 & $\mathbf{5 7 3 5}$ & 65,54 & Boa \\
\hline
\end{tabular}

* Pontos máximos possiveis e obtidos pelo total, ou seja, 25 internatos, também nas demais Tabelas do mesmo tipo.

pior é o "acesso às dependências" com 38,66 pontos para acesso por escadas, um recurso inadequado para o idoso.

"Acesso ao prédio" e "áreas de recreação" só podem ser considerados "regular", enquanto a "edificação", as "áreas externas". $\mathrm{e}$ as "dependências privativas dos residentes" conseguiram a classificação "boa".

A proporção da média geral sendo considerada "boa" diz que a planta física dos internatos estudados, de modo geral, corresponde a padrão satisfatório.
Quanto à situação dos internatos, à vista de sua capacidade física, ou seja, do seu número de leitos, vê-se na Tabela 2 como se comportam os valores encontrados para os grupos de leitos dos internatos. Destacase 0 de 60 a 100 leitos por conseguir para - total dos componentes da planta física uma percentagem de 82,85 e a classificação "ótima". O grupo de classificação mais precária é o de 40 a 60 leitos, com 55,71 ainda classificada como "regular", enquanto todos os demais grupos, inclusive o de 200 leitos e mais, se classificam como "boa". 
BASTIAN, E. M. Estudo sobre credenciamento de internatos para pessoas idosas. Rev. Saude públ., S. Pttulo, 14:439-53, 1980.

Em resumo, também sob o ponto de vista de numero de leitos, os grupos conseguem numa classificação geral "boa", demonstrando uma certa homogeneidacle de padrão para esta área.

\section{Instalaşós e Equipamentos}

Nota-se na Tabela 3 que se destaca a "sala de enfermagem" que aparece com uma percentagem de 68,00 como único recurso considerado "bom" entre as salas especificas.

Seguem as classificaçōes: "regular", "o gabinete médico", $52,00 \%$, e a "sala para entrevista", 48,00\%; "má", as de "fisioterapia", 20,00\%, e "odontologia", 10,00\%. A média de classificação só alcança um "regular", e este no limite de "má", com $40,80 \%$.

T A B E L A 2

Pontos máximos possíveis e pontos obtidos pelos internatos agrupados, referente ao item I, Planta Física, segundo número de leitos, na área metropolitana de Porto Alegre, RS, 1978 .

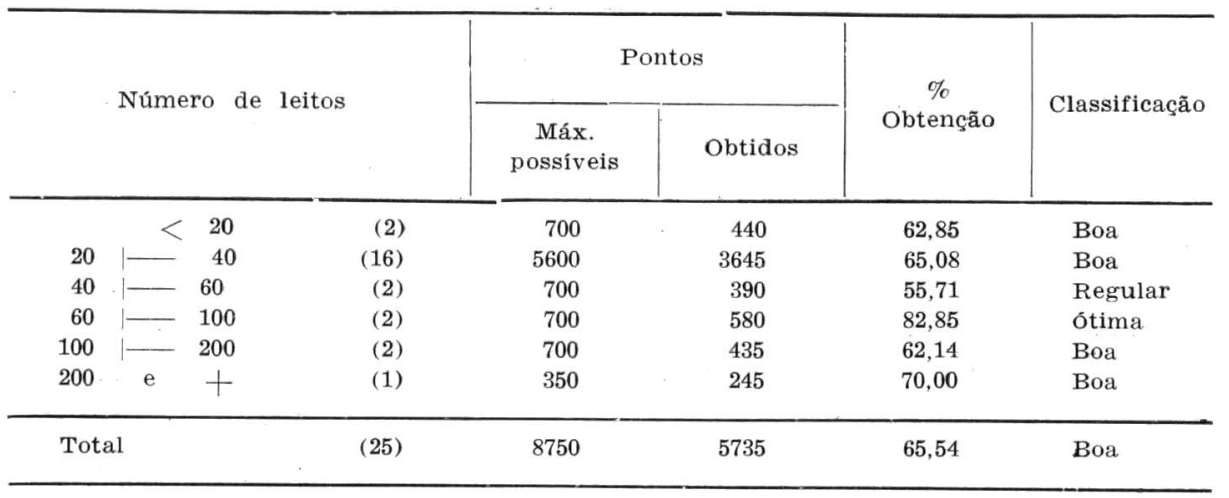

$(\quad)=$ unidades que se enquadram nos respectivos grupos de leitos.

$\mathrm{r}=0,35 ; \mathrm{t}=1,74$. Valor significante a nível de $5 \%$

T A B E L A 3

Pontos máximos possíveis e pontos obtidos pelos internatos agrupados, referente ao item II, Instalações e Equipamentos, segundo salas específicas, na área metropolitana de Porto Alegre, RS, 1978.

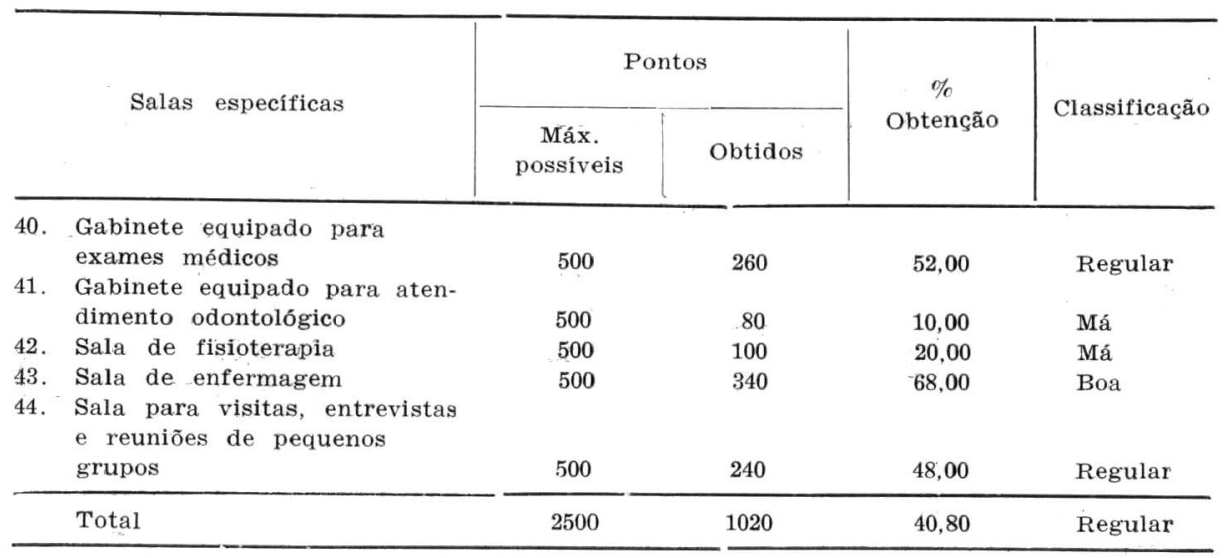


BASTIAN, E. M. Estudo sobre credenciamento de internatos para pessoas idosas. Rev. Saude publ., S. Paulo, 14:439-53, 1980.

Quanto à classificação por grupos de leitos, Tabela 4 , destaca-se o grupo de 200 e mais leitos como "ótimo", 100,00\%, de 40 a 60 leitos como "bom", 70,00\%, - de 100 a 200 leitos como "regular", $50,00 \%$, e os três grupos restantes, menos que 20,20 a 40 e 60 a 100 leitos, como "má", com respectivamente $10,00 \%, 36,26 \%$ e $40,00 \%$.
Portanto, os dois grupos de maior capacidade física dispõõem de instalações mais completas.

\section{Programação}

No que se refere às atividades ocupacio nais, verifica-se pela Tabela 5 que a percentagem dos pontos obtidos pelos inter-

T A B E L A 4

Pontos máximos possíveis e pontos obtidos pelos internatos agripados, referente ao item II, Instalações e Equipamentos, segundo número de leitos, na área metropolitana de Porto Alegre, RS, 1978.

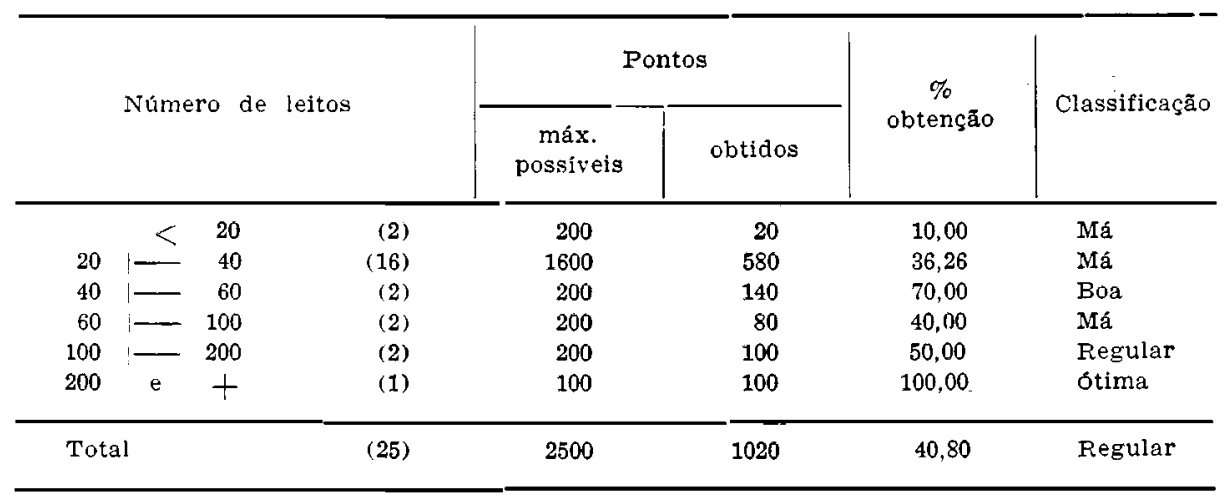

$r=0.36 ; t=1,85$. Valor significante a nivel de $5 \%$.

T A B E L A 5

Pontos máximos possiveis e pontos obtidos pelos internatos agrupados, referente ao item III, Programação, segundo atividades ocupacionais, recreativas e culturais na área metropolitana de Porto Alegre, RS, 1978.

\begin{tabular}{|c|c|c|c|c|c|}
\hline \multirow{2}{*}{\multicolumn{2}{|c|}{ Atividades ocupacionais }} & \multicolumn{2}{|c|}{ Pontos } & \multirow{2}{*}{$\begin{array}{c}\% \\
\text { obtenção }\end{array}$} & \multirow{2}{*}{ Classificação } \\
\hline & & $\begin{array}{c}\text { máx. } \\
\text { possiveis }\end{array}$ & obtidos & & \\
\hline 45. & Artesanatos & 500 & 60 & 12,00 & Má \\
\hline 46. & Trabalhos manuais & 500 & 300 & 60,00 & Regular \\
\hline 47. & Atividades hortigrangeiras & 500 & 80 & 16,00 & Má \\
\hline 48. & Exposiçōes & 250 & 100 & 40,00 & Má \\
\hline 49. & Jogos recreativos & 250 & 60 & 24,00 & Má \\
\hline 50 & Exercícios & 500 & 50 & 10.00 & Má \\
\hline 51. & Música & 250 & 110 & 44,00 & Regular \\
\hline 52. & Conferências & 250 & 100 & 40,00 & Má \\
\hline 53. & Cursos & 500 & 120 & 24,00 & Má. \\
\hline & Total & 3500 & 980 & 28,00 & Má \\
\hline
\end{tabular}


BASTIAN, E. M. Estudo sobre credenciamento de internatos para pessoas idosas. Rev. Saúde públ., S. Paulo, 14:439-53, 1980.

T A B E L A 6

Pontos máximos possíveis e pontos obtidos pelos internatos agrupados, referente ao item III, Programação, segundo número de leitos, na área metropolitana de Porto Alegre, RS, 1978.

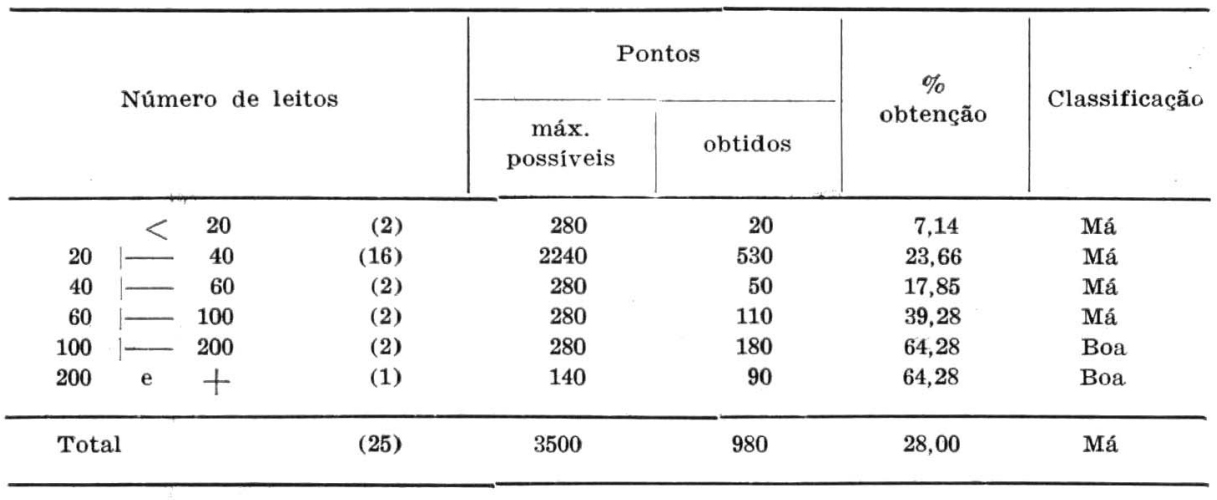

$r=0,59 ; t=3,50$. Valor significante a nível de $5 \%$.

natos em relação aos pontos máximos possiveis é bastante baixa. Assim, a melhor classificação, com "regular", é alcançada por "trabalhos manuais" com $60,00 \%$ dos internatos, e "música" com 44,00\%, enquanto todas as restantes atividades obtiveram a classificação "má".

Quanto à classificação dos grupos de estabelecimentos por número de leitos, a Tabela 6 revela um resultado bem de acordo com a idéia em que se baseia a pesquisa. Isto, porque, os dois grupos com o maior número de leitos, ou seja, 100 a 200 e 200 e mais leitos estão em grande vantagem na classificação referente à programação. Ambos os grupos obtiveram $64,28 \%$, enquanto todos os demais grupos, de internatos com menor capacidade física, ficam classificados como "má".

No total, os internatos só conseguem $28,00 \%$ das atividades que se espera sejam oferecidas aos residentes idosos; a classificação geral, portanto, é "má".

\section{Pessoal Técnico}

Como se observa na Tabela 7 , as classificações obtidas pelos internatos referentes ao seu pessoal técnico são bastante pre- cárias. Somente uma categoria está qualificada como "boa", que é o "atendente em turno diurno", com $61,00 \%$. Como é conhecido, este é um pessoal sem preparo, com niveis de instruçāo e sócio-cultural precário, sem condições de assistir o idoso na complexidade de suas necessidades.

Duas categorias chegam a um "regular", "médico em turno diurno", $60,00 \%$ (no limite de "boa") e o "auxiliar de enfermagem em turno diurno", com $42,66 \%$.

Todas as outras categorias só alcançam a classificação "má", resultado principalmente deplorável para os profissionais "enfermeira", "nutricionista" e "assistentes sociais", indispensáveis para uma assistência básica eficaz para este tipo de residentes, pessoas idosas em condições regulares de saúde, mas com os múltiplos problemas hin-psico-sociais próprins à sua idade.

$\mathrm{Na}$ Tabela 8 vê-se que o grupo de 200 leitos e mais, portanto de capacidade física maior, obteve, com a percentagem 61,00 a classificação "boa". Todos os outros grupos são qualificados como "má". Naturalmente, a proporção da média dos internatos com 20,44\% é "má". 
BASTIAN, E. M. Estudo sobre credenciamento de internatos para pessoas idosas. Rev. Saudo públ., S. Paulo, 14:439-53, 1980.

TAB E L A 7

Pontos máximos possiveis e pontos obtídos pelos internatos agrupados, referente ao item IV, Pessoal Técnico, segundo categorias profissionais e auxiliares, na área metropolitana de Porto Alegre, RS, 1978.

\begin{tabular}{|c|c|c|c|c|}
\hline \multirow{2}{*}{$\begin{array}{c}\text { Categorias profissionais e } \\
\text { auxiliares }\end{array}$} & \multicolumn{2}{|c|}{ Pontos } & \multirow{2}{*}{$\stackrel{\%}{\text { obtenção }}$} & \multirow{2}{*}{ Classificação } \\
\hline & $\begin{array}{l}\text { máx. } \\
\text { possiveis }\end{array}$ & obtidos & & \\
\hline 54. Médico em turno diurno & 500 & 300 & 60.00 & Regular \\
\hline 55. Médico em turno noturno & 1000 & 200 & 20,00 & Má \\
\hline 56. Odontólogo & 500 & 60 & 12,00 & Má \\
\hline $\begin{array}{l}57 \text { e 58. Enfermeiro em turno } \\
\text { diurno }\end{array}$ & 1000 & 100 & 10.00 & Má \\
\hline $\begin{array}{l}59 \text { e } 60 . \text { Enfermeiro em turno } \\
\text { noturno }\end{array}$ & 1000 & - & 一 & Má \\
\hline $\begin{array}{l}61 \text { e 62. Auxiliar de enfermagem } \\
\text { em turno diurno }\end{array}$ & 750 & 320 & 42,66 & Regular \\
\hline $\begin{array}{l}\text { 68 e 64. Auxiliar de enfermagem } \\
\text { em turno noturno }\end{array}$ & 750 & 105 & 14,00 & Má \\
\hline $\begin{array}{l}65 \text { e } 66 \text {. Fisioterapeuta e auxiliar } \\
\text { de fisioterapia }\end{array}$ & 500 & 80 & 16,00 & Má \\
\hline 67. Assistente Social & 1000 & 120 & 12,00 & Má \\
\hline 68. Recreador & 250 & 80 & 32,00 & Má \\
\hline 69. Terapeuta ocupacional & 500 & 120 & 24,00 & Má \\
\hline $\begin{array}{l}\text { 70. Orientador de trabalhos ma- } \\
\text { nuais }\end{array}$ & 500 & 100 & 20,00 & Má \\
\hline 71. Nutricionista ou dietista & 1000 & 80 & 8,00 & Má \\
\hline $\begin{array}{l}72 @ 73 . \text { Atendentes em turno } \\
\text { diurno }\end{array}$ & 500 & 305 & 61,00 & Boa \\
\hline $\begin{array}{ll}74 \text { e } 75 . & \begin{array}{l}\text { Atendentes em turno } \\
\text { noturno }\end{array} \\
\end{array}$ & 500 & 125 & 25,00 & Má \\
\hline Total & 10250 & 2095 & 20,44 & Má \\
\hline
\end{tabular}

Devido a grande importância dos dois ítens "programação" e "pessoal técnico" no atendimento dos idosos, os valores de credenciamento, quando observado o total dos internatos estudados, repercutem em sentido bastante negativo para estes estabelecimentos.

\section{Planta Fisica, Instalą̧ōes e Equipamentos, Programação e pessoal Técnico}

Nas Tabelas 9 e 10 estão apresentados os resultados obtidos referente ao conjunto das áreas investigadas. Vê-se na Tabela 9 a classificação dos internatos de acordo com os valores de credenciamento conseguidos conforme áreas. Comparando-se estes valores com os máximos possíveis, observase que a "planta física" recebe a classificação "boa", com $65,54 \%$; "instalações e equipamentos" corresponde, com $40,80 \%$, a $\mathrm{um}$ fraco "regular", no limite de "má". Também as áreas de "programação" e de "pessoal técnico" são muito deficientes, conseguindo $28,29 \%$ e $20,43 \%$ respectivamente, 
BASTIAN, E. M. Estudo sobre credenciamento de internatos para pessoas idosas. Rer. Saúdo píbl., S. Paulo, 14·439-53. 1980.

T A B ELA 8

Pontos máximos possíveis e pontos obtidos pelos internatos agrupados, referente ao item IV, Pessoal Técnico, segundo número de leitos, na área metropolitana de Porto Alegre, RS, 1978.

\begin{tabular}{|c|c|c|c|c|c|c|c|}
\hline & \multicolumn{3}{|c|}{ Número de leitos } & \multicolumn{2}{|c|}{ Pontos } & $\begin{array}{c}\% \\
\text { obtenção }\end{array}$ & Classificação \\
\hline & $<$ & 20 & (2) & 820 & 25 & 3,04 & Má \\
\hline 20 & 1 & 40 & (16) & 6560 & 1310 & 19,96 & Má \\
\hline 40 & - & 60 & (2) & 820 & 210 & 25,60 & Má \\
\hline 60 & 1 & 100 & (2) & 820 & 210 & 25,60 & Má \\
\hline 100 & L- & 200 & (2) & 820 & 65 & 7,92 & Má \\
\hline 200 & $\mathrm{e}$ & + & (1) & 410 & 275 & 67,07 & Boa \\
\hline Tot & & & (25) & 10250 & 2095 & 20,44 & Má \\
\hline
\end{tabular}

$\mathrm{r}=0,21 ; \mathrm{t}=1,03$. Valor não significante a nível de $\mathbf{5 \%}$.

T A B E L A 9

Pontos máximos possíveis e pontos obtidos pelos internatos agrupados, referente aos itens I a IV, na área metropolitana de Porto Alegre, RS, 1978.

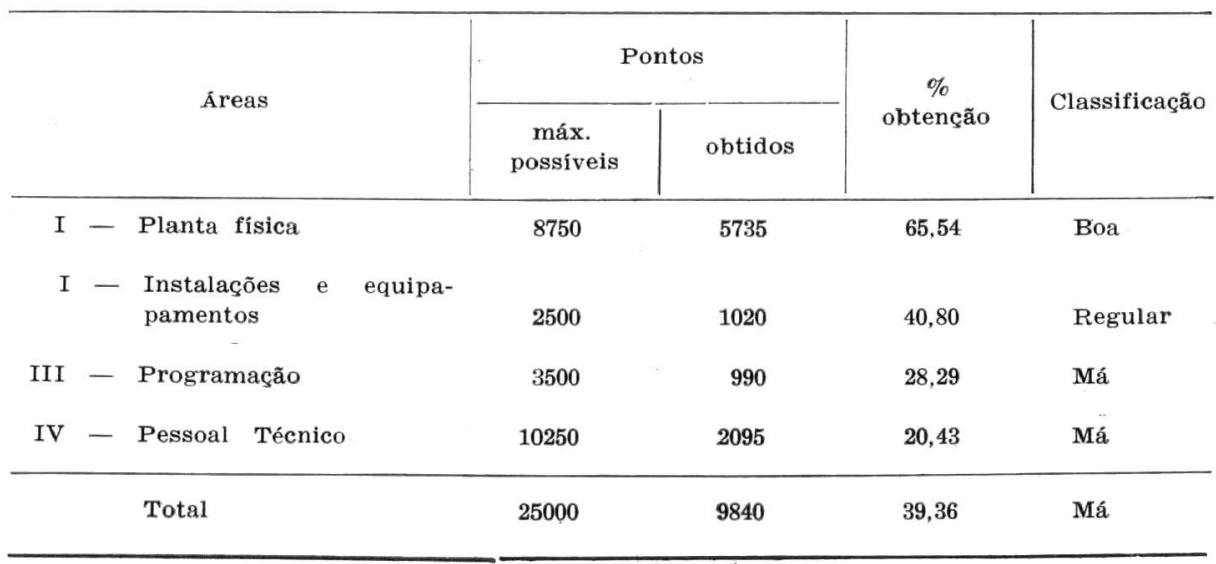

classificadas como "má". Assim, a proporção da média das 4 áreas está com $39,66 \%$, classificadas como "má".

Quanto aos grupos de leitos, Tabela 10 , verifica-se que 0 grupo de 200 leitos e mais conseguiu a melhor classificação, "boa", com $71 \%$ para o total de áreas. Classifica-se o grupo de 80 a 100 leitos com $49,50 \%$ como "regular"; os demais grupos são qualificados como "má", variando entre $25,24 \%$ e $39,50 \%$.

Examinando os resultados obtidos nesta pesquisa e fazendo inferência à capacidade ótima dos internatos segundo opinião de Hay ${ }^{5}, 1975$ - 180 leitos - verificamos que o grupo de maior número de leitos, 
BASTIAN, E. M. Estudo sobre credenciamento de internatos para pessoas idosas. Rev. Saúde públ., S. Paulo, 14:439-53, 1980.

T A B E L A 10

Pontos máximos possíveis e pontos obtidos pelos internatos agrupados, referente aos itens I a IV, segundo número de leitos, na área metropolitana de Porto Alegre, RS, 1978.

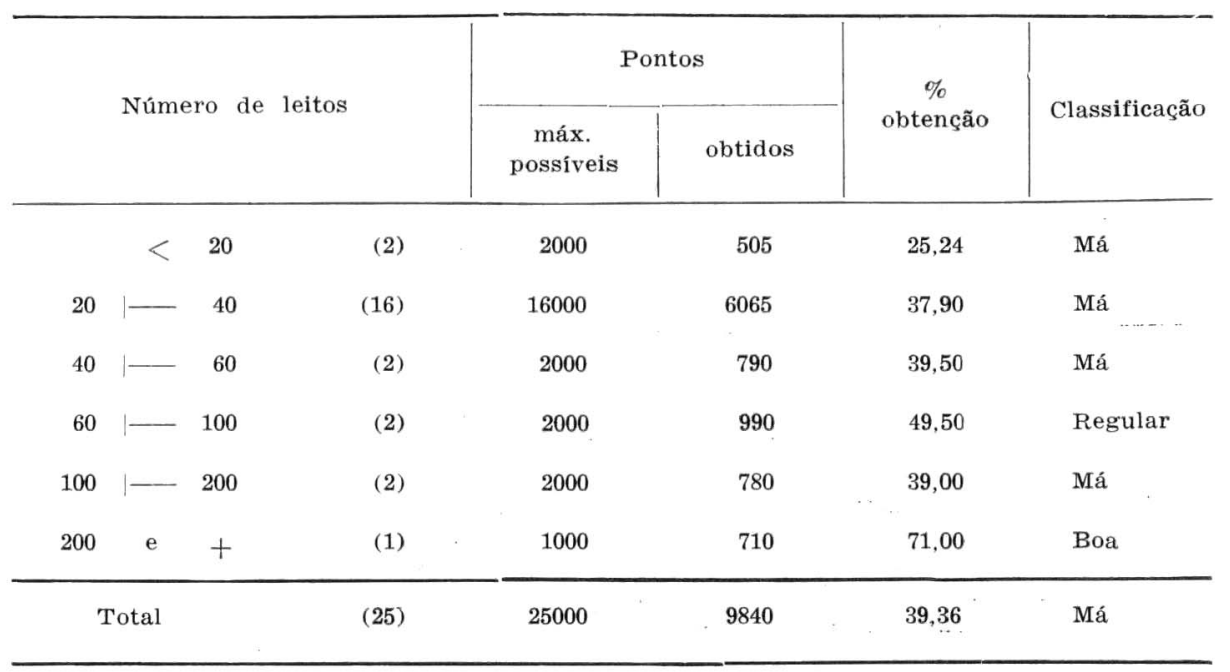

$\mathbf{r}=0,42 ; \mathrm{t}=2,22$. Valor significante a nível de $5 \%$.

200 e mais, e individualmente 0 internato com 210 leitos, obteve o maior número de pontos, ou seja, 710 por unidade, seguido somente por 495 pontos do grupo de 60 a 100 leitos, apontando uma capacidade em torno de 210 leitos como a mais satisfatória, ou que mais se aproxima àquela condição.

Correlação entre os valores de credenciamento e a capacidade física dos internatos

Com referência à hipótese de uma possivel correlação positiva entre os valores de credenciamento e o número de leitos atribuidos aos internatos, verificou-se que existe uma correlação significante ao nivel de $5 \%$. Este fato significa que internatos para pessoas idosas na área metropolitana de Porto Alegre, com maior capacidade física, no sentido de major número de leitos, dispõem de recursos mais completos para a assistência a ser prestada ans sells residentes.

O mesmo nível de significância foi obtido para as áreas: planta física, instalaçōes e equipamentos e as atividades programadas.
No caso do pessoal técnico, não houve correlação significante ao nivel de $5 \%$. Os internatos, portanto, com grande número de leitos não contam com maiores recursos de pessoal técnico para a assistência às pessoas idosas, sob sua responsabilidade, do que os estabelecimentos menores.

\section{CONCLUSOES}

1) A pesquisa corrobora a idéia de que internatos com capacidade física maior tendem a dispor de recursos mais completos para assistir ao idoso do que internatos pequenos.

2) Este fato significa que internatos para pessoas idosas na área metropolitana de Porto Alegre, de modo geral, dispõem de recursos mais completos para a assistência a ser prestada ans seus residentes.

3) Os internatos com grande número de leitos não contam com maiores recursos de pessoal técnico para assistência do que os estabelecimentos menores. 
BASTIAN, E. M. Estudo sobre credenciamento de internatos para pessoas idosas. Rev. Saude públ., S. Paulo, 14:439-53, 1980.

RSPUB9/522

BASTIAN, E. M. [Accreditation of home for the agead.] Rev. Saúde públ., S. Pallo, 14:439-53, 1980 .

ABSTRACT: A study was carried out to verify if the larger homes for senior citizens, i.e., those with the larger number of beds, offer complete assistance to their residents. Four aspects were examined: the building proper, its installations and equipments, its technical personnel, and the programming of activities. A majority of these aspects were found satisfactory.

UNITERMS: Home for the aged.

\section{REFERENCIAS BIBLIOGRAFICAS}

1. BAStian, E. M. Estudo de aspectos de assistência à saúde da pessoa idosa em instituições não hospitalares no no município de São Paulo, Brasil. Rev. Saíde públ., S. Paulo, 11:444-54, 1977.

2. BEATTY JR. W. M. \& BULLOK, J. Evaluating services and personnel in facilities for the aged. In: Leeds, $M$. \& Shore, H. Geriatric institutional management. New York, Putnam's Sons, 1964.

3. CIARI JR., C. et al. "Acreditação" de serviços de pré-natal. Rev. Sarude públ., S. Paulo, 8:187-202, 19974.

4. GREENWALD, S. R. \& LINN, M. W. Intercorrelation of data on nursing homes. Gerontologist, 11:337-40, 1971.

5. HAY, D. G. Profiles of three nursing homes and a longterm hospital in Scandinavia. Gerontologist, 15:297-303, 1975 .

6. HERZ, K. G. Community resources and services to help independent living. Gerontologist, 2:59-66, 1971.

7. HOLLE, H. A. The meaning of accreditation. In: Jacobs, H. L. \& Morris, W. W. Nursing and retirement home administration. Iowa, Iowa University Press, 1968.

8. INSTITUTO NACIONAL DE PREVIDINCIA SOCIAL. Resoluça no 499.30, de 19 de novembro de 1974; (BS/DG 225, de 22/11/79). Brasillia, 1974.

9. INSTITUTO NACIONAL DE PREVIDEN. CIA SOCIAL. Sistema Nacional de Previdencia Social: SINPAS. Brasilia, 1977.
10. KARCHER, D. J. \& LINDEN, L. L. Family rejection of the aged and nursing home utilization. Int. J. Aging hum. develop., 5:231-44, 1974.

11. LEEDS, M. \& SHORE, H. Geriatric institutional management. New York, Putnam's Sons, 1964.

12. MUENCHEN Landeshauptstadt Sozial Referat. Problem studie zur Situation alter Menschen in Muenchen. Muenchen, 1972.

13. NURSING home surveyers are trained under HSMHA contracts. Hith Serv. Rep., 87 :255-61, 1972.

14. ORGANIZACION MUNDIAL DE LA SALUD, Comité de Expertos en Planificacion de los Servicios Geriatricos, Genebra, 1973. Informe. Ginebra, 1974. (Ser. Inf. tecn., 548).

15. SECRETARIA DO TRABALHO E AÇAO SOCIAL DO ESTADO. Catálogo de Obras Sociais da Região Metropolitana de Porto Alegre. Porto Alegre, 1976.

16. SIROCCO, A. Services and activities offered to nursing home residents. Unites States: 1968. Vital Hlth Statist., Ser. 12, (17), 1972.

17. La VEJEZ como problema social. Crón. OMS, $28(11): 534-42,1974$.

18. WEIHL, H. \& ASHKENAZI, J. Satisfaction of old age inhabitants with the home. Gerontology, Tel-Aviv, 1:66-75, 1975.

Recebido para publicagão em 02/04/1980 Aprovado para publicação em 12/09/1980 
BASTIAN, E. M. Estudo sobre credenciamento de internatos para pessoas idosas. Rev. Saude públ., S. Paulo, 14:439-53, 1980.

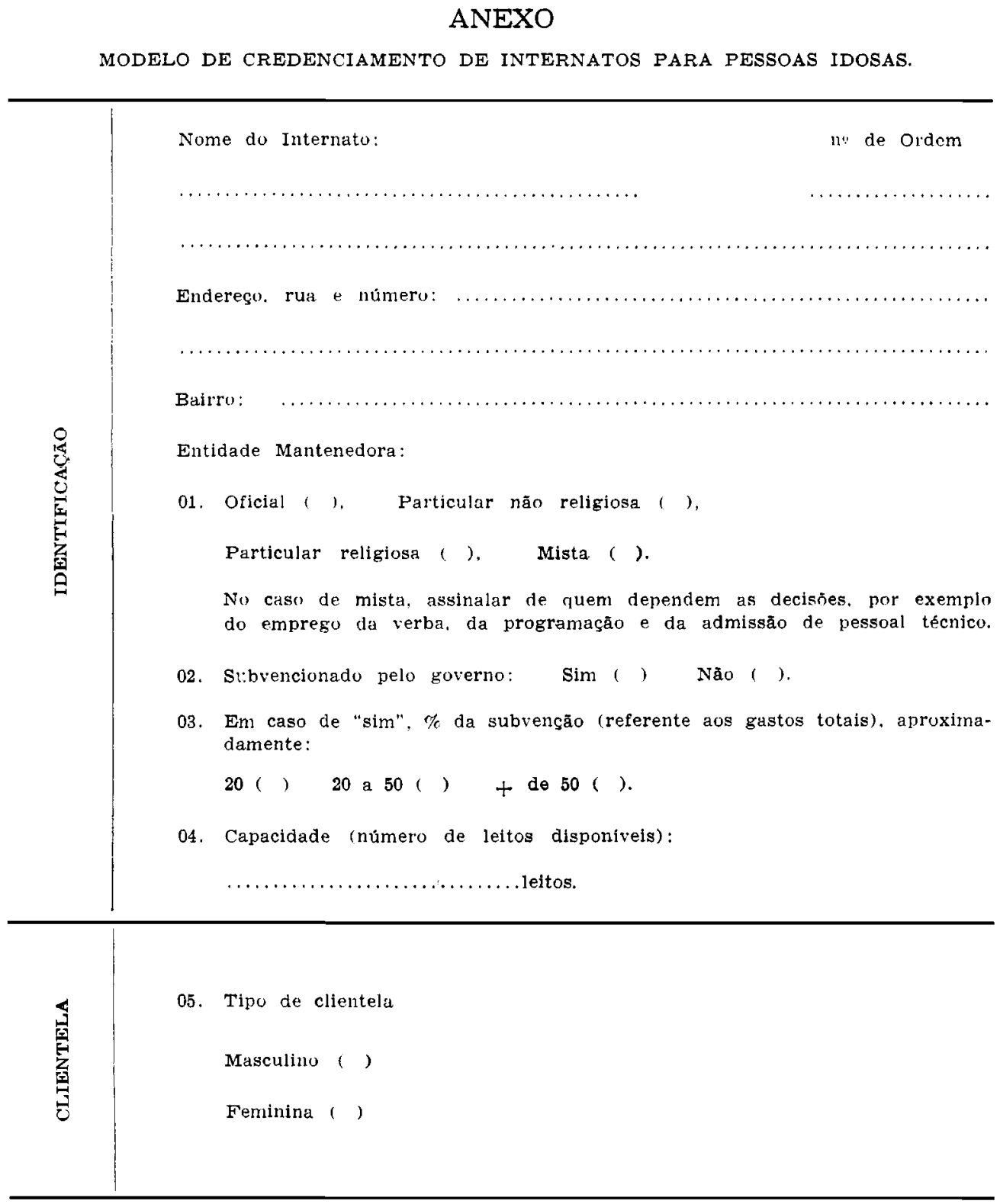


BASTIAN, E. M. Estudo sobre credenciamento de internatos para pessoas idosas. Rev. Saude públ., S. Paulo, 14:439-53, 1980.

I - PLANTA FISICA

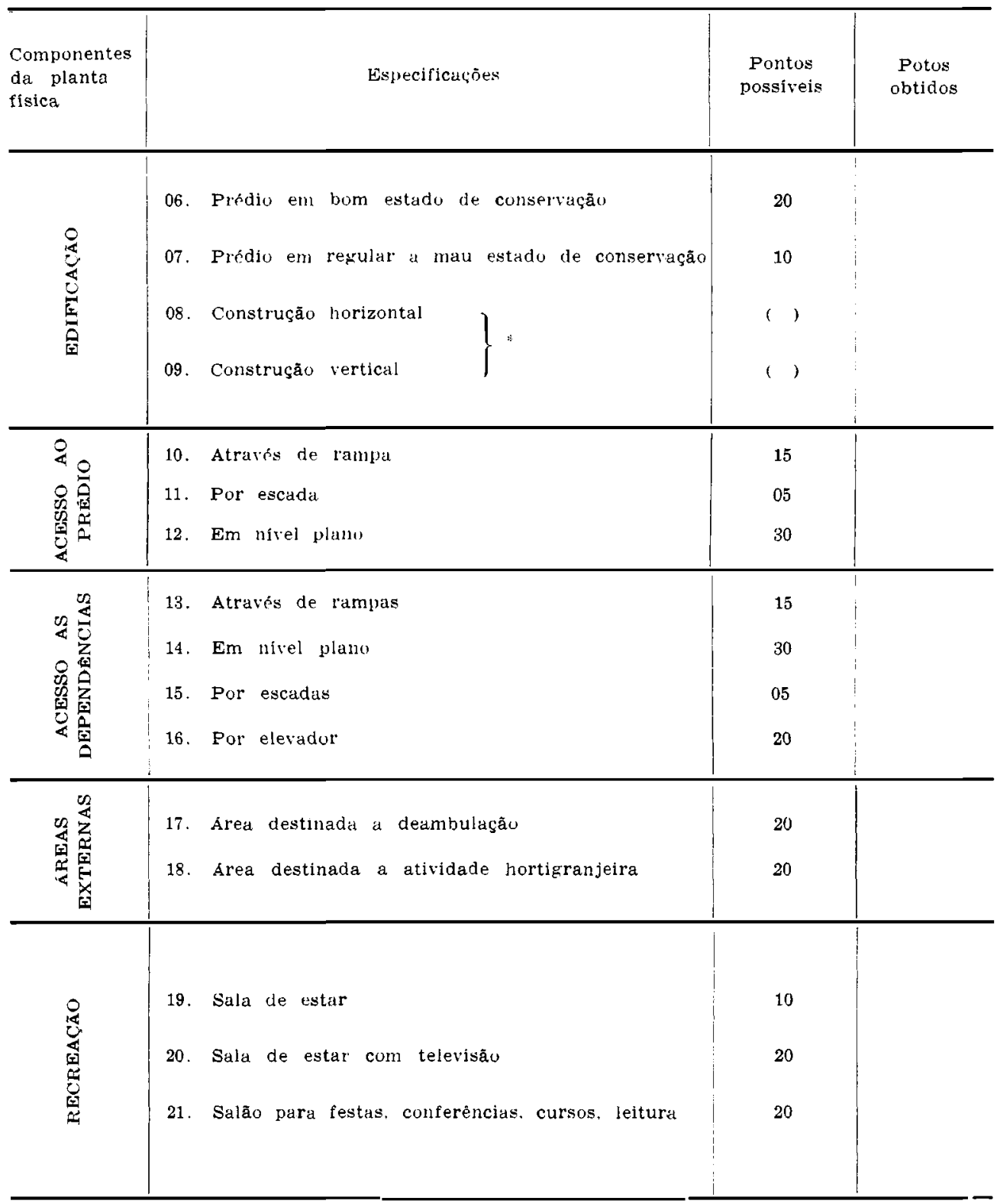

* Colocar um " $\mathrm{X}$ " entre os parênteses da especificaçảo que se aplica 
BASTIAN, E. M. Estudo sobre credenciamento de internatos para pessoas idosas. Rev. Saude públ., S. Paulo, 14:439-53, 1980.

I - Planta Fisica (Continuação)

\begin{tabular}{|c|c|c|c|}
\hline $\begin{array}{l}\text { Componentes } \\
\text { da planta } \\
\text { física }\end{array}$ & Especificaçōes & $\begin{array}{l}\text { Pontos } \\
\text { possiveis }\end{array}$ & $\begin{array}{l}\text { Pontos } \\
\text { obtidos }\end{array}$ \\
\hline 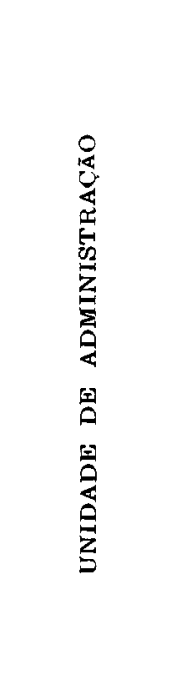 & $\begin{array}{l}\text { 22. Areas individualizadas para serviços administra- } \\
\text { tivos (escritórios) } \\
\text { 23. Recepçấo } \\
\text { 24. Chuveiros, sanitários e lavatórios para funcionários } \\
\text { 25. Vestiário para funcionários } \\
\text { 26. Copa } \\
\text { 27. Copa e dispensa } \\
\text { 28. Copa dispondo de req: isitos para guarda e con- } \\
\text { 29. Rouparia } \\
\text { 30. Lavadora } \\
\text { 31. Lavanderia e rouparia } \\
\text { 32. Cozinha. }\end{array}$ & $\begin{array}{l}10 \\
10 \\
10 \\
10 \\
05 \\
10\end{array}$ & \\
\hline 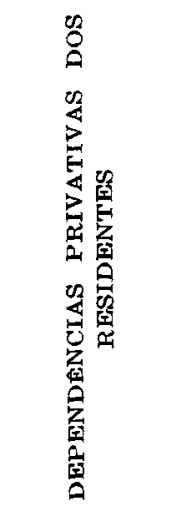 & $\begin{array}{l}\text { 33. Refeitório } \\
\text { 34. Quartos para até } 02 \text { pessoas } \\
\text { 35. Quartos para até } 04 \text { pessoas } \\
\text { 36. Quartos para mais de } 04 \text { pessoas } \\
\text { 37. Banheiros completos, um para cada } 02 \text { pessoas } \\
\text { 38. Lavatórios, chuveiros, banheiros e sanitários, um } \\
\text { para cada } 06 \text { pessoas } \\
\text { 39. tdem para mais de } 06 \text { pessoas }\end{array}$ & $\begin{array}{l}40 \\
20 \\
05 \\
40 \\
20\end{array}$ & \\
\hline
\end{tabular}


BASTIAN, E. M. Estudo sobre credenciamento de internatos para pessoas idosas. Rer. Saúde puibl., s. Paulo, 14:439-53, 1980.

\section{II - INSTALACOOES E EQUIPAMENTOS}

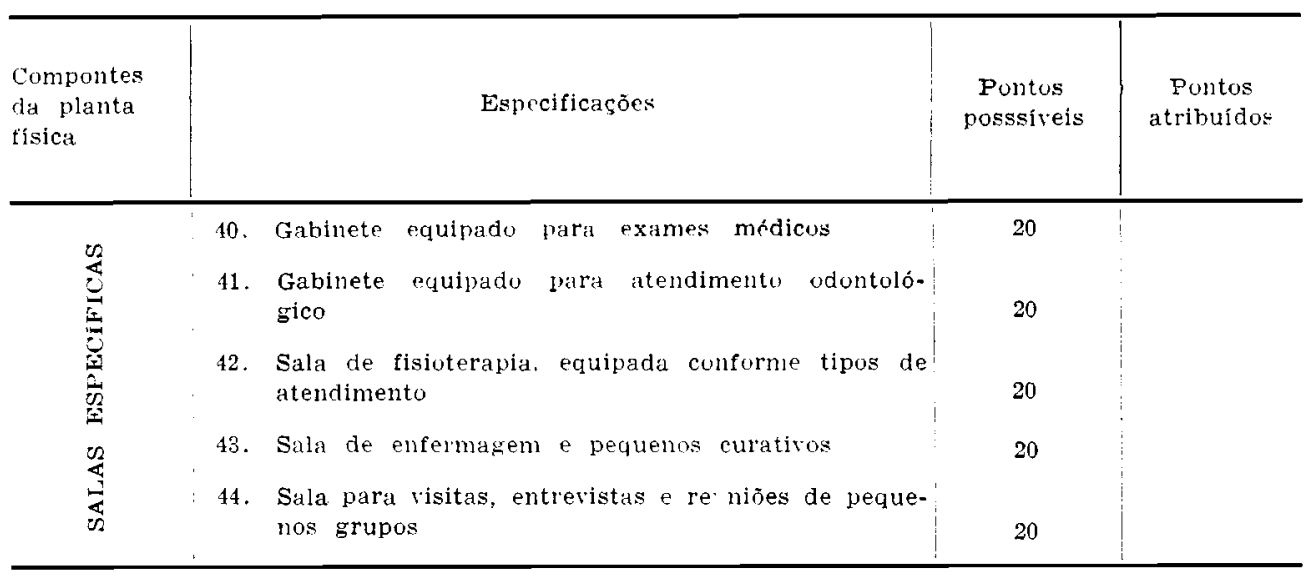

111 - PROGRAMAÇÃO

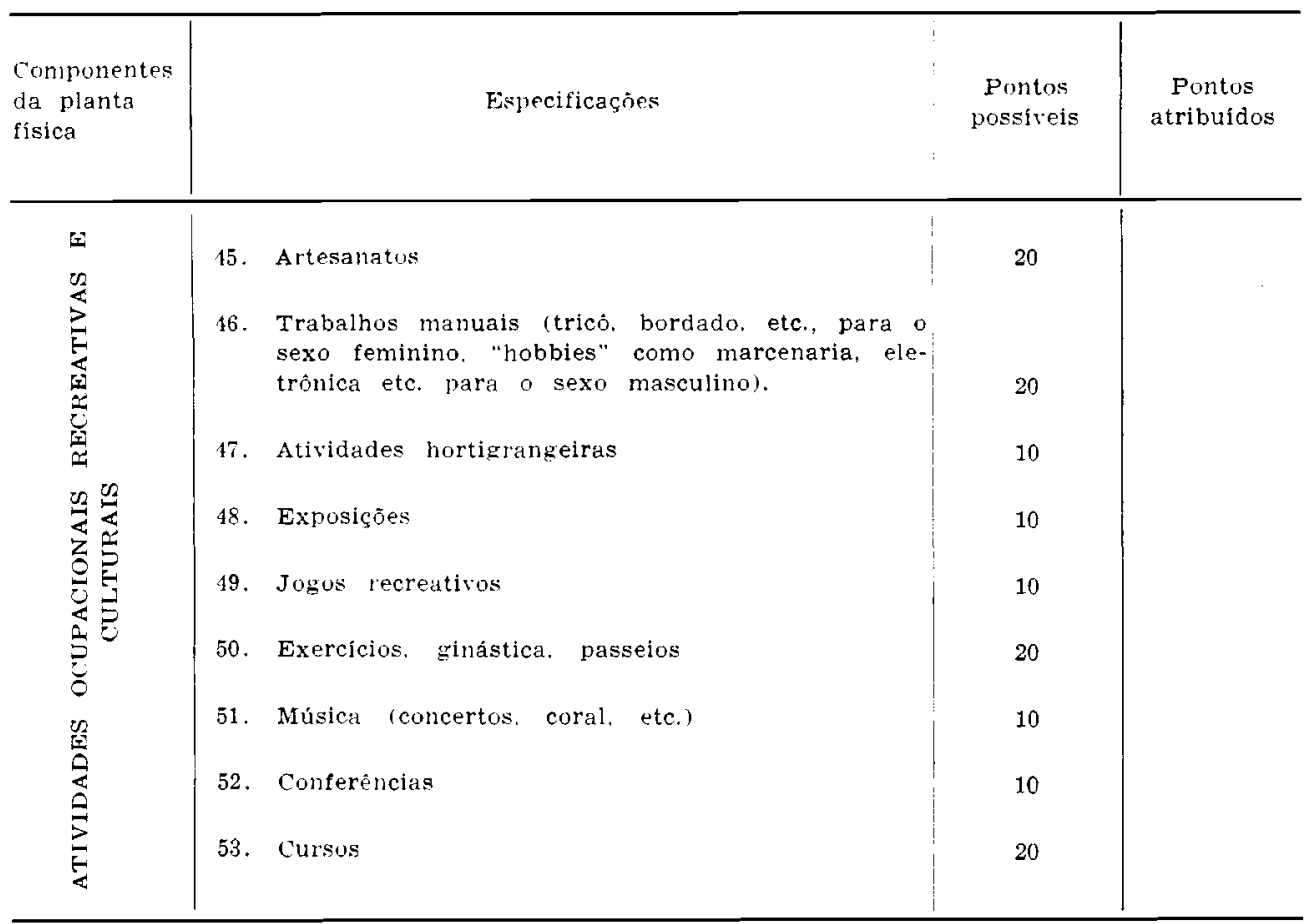


BASTIAN. E. M. Estudo sobre credenciamento de internatos para pessoas idosas. Rev. Saude puibl., \$. Paulo, 14:439-53, 1980.

IV - PESSOAL TECNICO

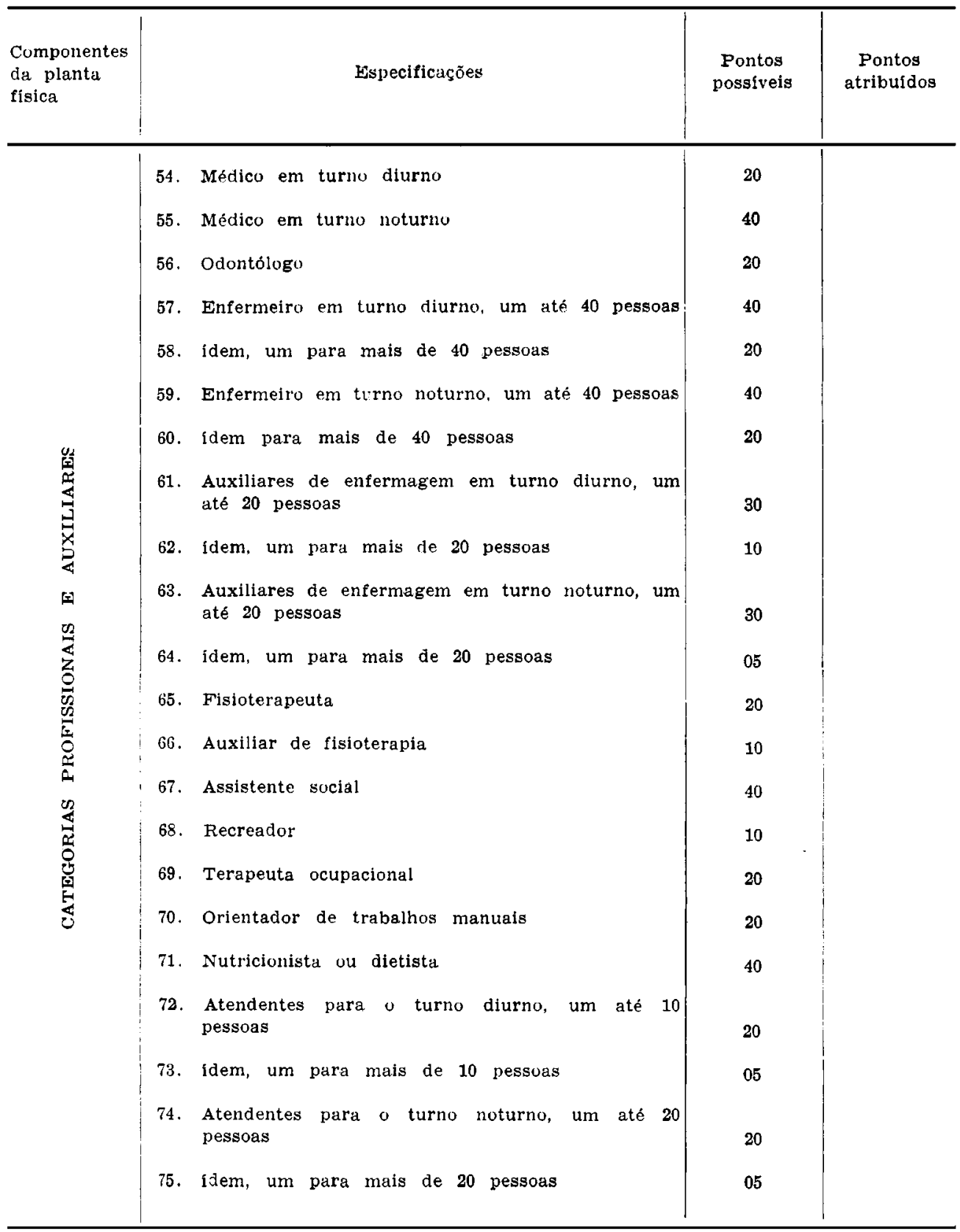

